\title{
Targeted therapies for renal cell carcinoma in Chinese patients: focus on everolimus
}

This article was published in the following Dove Press journal:

OncoTargets and Therapy

29 January 2015

Number of times this article has been viewed

\author{
Xiaojie Tan ${ }^{1, *}$ \\ Yan Liu',* \\ Jianguo $\mathrm{Hou}^{2}$ \\ Guangwen $\mathrm{Cao}^{\prime}$ \\ 'Department of Epidemiology, \\ Second Military Medical University, \\ 2Department of Urology, Changhai \\ Hospital, Second Military \\ Medical University, Shanghai, \\ People's Republic of China \\ *These authors contributed equally \\ to this work
}

\begin{abstract}
Renal cell carcinoma (RCC) is the most common type of cancer arising from the kidney, with a male to female ratio of 2:1. The incidence of RCC is rising. In males, it was the seventh most common cancer in the People's Republic of China in 2012. RCC is resistant to radiotherapy and chemotherapy, but approximately $20 \%$ of patients with advanced RCC respond to immunotherapy. Novel therapies targeting angiogenesis and signaling pathways have been proven to be effective for advanced or metastatic RCC in Western countries. Due to the heterogeneity of RCC between races, it is necessary to have an overview of targeted therapies, especially everolimus, for patients with advanced RCC in the People's Republic of China. Three targeted therapeutic agents have been approved in Mainland China for the treatment of patients with advanced RCC, ie, two tyrosine kinase inhibitors (sorafenib and sunitinib) and one mammalian target of rapamycin (mTOR) inhibitor (everolimus). Compared with Western patients with advanced or metastatic RCC, Chinese patients with the same disease respond better to sorafenib and sunitinib as first-line targeted therapy, but sunitinib has a relatively higher risk of toxicity. Everolimus, an mTOR inhibitor that can be administered orally, is well tolerated and acceptable to Chinese patients. Everolimus has competitive advantages as second-line targeted treatment for Chinese patients with advanced RCC who are resistant to first-line tyrosine kinase inhibitors. Despite a lack of noninferiority when compared with sunitinib as first-line therapy, the sunitinib-everolimus paradigm is still recommended as standard therapy for patients with advanced RCC. Although most studies of targeted therapies for advanced RCC have obvious limitations, such as small sample size and retrospective design, up-to-date evidence indicates that everolimus would be an ideal agent as second-line targeted treatment for advanced or metastatic RCC in the People's Republic of China.
\end{abstract}

Keywords: target therapy, renal cell carcinoma, everolimus, People's Republic of China

\section{Introduction}

Renal cell carcinoma ( $\mathrm{RCC}$ ) is the most common type of cancer arising from the kidney, and its incidence is steadily rising by about $2 \%$ per year. ${ }^{1} \mathrm{RCC}$ is more common in males than in females (ratio 2:1), and most often occurs in patients aged 50-70 years. A total of 66,466 new cases of kidney tumors were diagnosed in the People's Republic of China in 2012, which represents almost twice the number diagnosed in the USA. However, the incidence of kidney tumors in the People's Republic of China is still lower than the global incidence rate on average. This difference may result from environmental exposure and genetic predisposition. Further, the incidence of kidney tumors in males was listed as the seventh most common type of cancer in the People's Republic of China in 2012 . $^{2}$ Surgery is the mainstay of curative treatment if the patient can be diagnosed early. Compared with liver cancer and other aggressive cancers, RCC usually has a good prognosis following curative surgery. Up to $30 \%$ of RCC patients present with metastatic disease and have a median survival of 7-11 months.
Correspondence: Guangwen Cao Department of Epidemiology, Second Military Medical University, 800 Xiangyin Rd, Shanghai 200433, People's Republic of China Tel +86 2l 8I87 I060 Email gcao@smmu.edu.cn 
RCC is resistant to chemotherapy and radiotherapy. Approximately $20 \%$ of patients with advanced RCC respond efficiently to interleukin-2-based immunotherapy. Targeted therapies are the major systematic approach for advanced or metastatic RCC in Western countries. Currently, there are two kinds of therapeutic agents applied in targeted therapy for RCC, ie, tyrosine kinase inhibitors (TKIs) targeting tumor angiogenesis and mammalian target of rapamycin (mTOR) inhibitors. Sorafenib is the first approved TKI that has been recommended as first-line or second-line treatment for stage IV RCC, recurrent RCC, and metastatic RCC by the US Food and Drug Administration (FDA) since 2005. ${ }^{3}$ Thereafter, several TKIs, mainly targeting the vascular endothelial growth factor (VEGF) receptor or platelet-derived growth factor receptor, including sunitinib, pazopanib, and axitinib, as well as the anti-VEGF monoclonal antibody, bevacizumab, have been applied to targeted therapy for this malignancy worldwide. Everolimus, which is designed to target mTOR pathways, has also been approved as second-line treatment after TKI treatment failure and has had great clinical benefit for patients who are refractory to first-line targeted therapy. Temsirolimus, also targeting mTOR pathways, has been recommended as a category 1 agent for first-line treatment of RCC patients of poor prognosis, predominantly for unresectable clear cell stage IV or non-clear cell RCC.

However, the situation regarding targeted therapy, in particular everolimus, for advanced or metastatic RCC in the People's Republic of China remains largely unknown. RCC is a highly heterogeneous tumor and the effect of targeted therapy may differ between races, ${ }^{4,5}$ so it is necessary to summarize the progress made regarding targeted therapy in the People's Republic of China and provide evidence for standardizing the procedure for treating advanced RCC. Although many international clinical trials of targeted agents including sorafenib, sunitinib, everolimus, axitinib, temsirolimus, and pazopanib have been registered or performed in Mainland China, only three therapeutic agents are approved by the Chinese FDA for the treatment of advanced RCC, ie, two TKIs (sorafenib and sunitinib) and one mTOR inhibitor (everolimus). Further, according to related English publications on PubMed and major scientific publications in Chinese, outcomes of clinical trials for agents not approved in the People's Republic of China have not been reported independently. Although the clinical studies of the agents approved in Mainland China are relatively less extensive compared with those in Western countries, the primary results obtained so far are important in terms of improving the targeted therapies for this malignancy in the People's Republic of China.

\section{Sorafenib}

Sorafenib, the most popular multitargeting TKI, was approved as a first-line and second-line therapeutic agent for advanced RCC by the Chinese FDA in November 2006. The clinical benefit rate (complete response, partial response, and stable disease) in Chinese RCC patients in four studies ${ }^{6-9}$ published in international journals ranged from $80.0 \%$ to $88.1 \%$, which was similar to that in the TARGET (Treatment Approach in Renal Cancer Global Evaluation Trial), ${ }^{3}$ EU-ARCCS (European Renal Cell Carcinoma Sorafenib program), ${ }^{10}$ and NA-ARCCS (North America Renal Cell Carcinoma Sorafenib program) trials. ${ }^{11}$ Further, the objective response (complete response and partial response) was much higher in Chinese patients $(21 \%-36.6 \%)$ than in Western populations $(4 \%-10.2 \%)$. This favorable outcome also included prolonged progression-free survival (PFS), with medians ranging from 9.6 weeks to 15 weeks. A similar trend has been observed in Japanese and Korean patients. ${ }^{12,13}$ Hand-foot syndrome, diarrhea, fatigue, loss of appetite, and alopecia are the most common adverse effects of sorafenib in Chinese patients, and are usually manageable. Further, compared with Western patients, Chinese patients with RCC tend to derive more clinical benefit and have fewer adverse effects with an increasing dosage of sorafenib. The clinical benefit rate can reach $80 \%$ or more with dose escalation of sorafenib to $1,200 \mathrm{mg}$ or $1,600 \mathrm{mg}$ daily or $600 \mathrm{mg}$ twice a day in patients who have experienced failure on sorafenib at a conventional dosage. ${ }^{14}$ However, dose escalation of sorafenib might have a negative impact on tolerance. The optimal maximum tolerated dosage to gain more clinical benefit without a significant increase in adverse effects needs to be verified in long-term clinical studies with large sample sizes. Thus, sorafenib can be more effective in Chinese patients than in Western patients and well tolerated if high dosages are administered. ${ }^{15}$

\section{Sunitinib}

Sunitinib is another multitargeting TKI, and was approved by the Chinese FDA in May 2008. Sunitinib is a gold standard first-line treatment for advanced RCC internationally. ${ }^{16}$ The efficacy and toxicity of sunitinib have rarely been reported in Chinese patients with RCC. In 2012, Ye et al ${ }^{17}$ reported a prospective, multicenter, single-arm, Phase IV clinical trial of standard application of sunitinib in patients with advanced RCC in Mainland China. Of 105 patients enrolled, the disease control rate was $76.9 \%$, the objective response was $31.1 \%$, and the median PFS was 13.5 months. The objective response rate and median PFS were $31 \%$ and 11 months, respectively, 
in Western patients. ${ }^{18,19}$ More recently, He et al ${ }^{20}$ reported a study of 141 patients with metastatic RCC, including 119 patients who received single-agent sunitinib as first-line therapy and 22 patients who received it as second-line therapy at two Chinese centers. The clinical benefit rate was $87.2 \%$, the objective response rate was $26.9 \%$, and median PFS was 14.2 months. The two Chinese studies reported a longer PFS than that in Western patients. However, the objective response rate did not show an obvious increase. Further, $36.9 \%$ of the patients needed dose reduction or treatment interruption because of adverse effects. ${ }^{20}$ The most common adverse effects were thrombocytopenia, hypothyroidism, neutropenia, hand-foot syndrome, and hypertension. Yoo et $\mathrm{al}^{21}$ also reported that Korean RCC patients receiving sunitinib therapy had a higher incidence of adverse events than Western patients, with $46 \%$ requiring dose reduction. Genetic polymorphism in the ABCG2 gene ( $421 \mathrm{C}>\mathrm{A})$ may contribute to sunitinib-related toxicity in Korean patients with metastatic RCC. ${ }^{22}$ Toxicity profiles related to racial differences need to be investigated further. Careful follow-up is necessary to ensure continuation of sunitinib therapy. ${ }^{23}$ Thus, sunitinib has a therapeutic effect comparable with that of sorafenib, but has a more severe toxicity profile in Asian patients than in Western patients. The toxicities of sunitinib in Asians might be determined by genetic predisposition.

\section{Everolimus}

Despite the tremendous improvements in targeted therapies for metastatic RCC, it has been reported that most patients develop resistance to anti-VEGF therapy after 6 months to 3 years of disease control, and eventually die after disease relapse. ${ }^{24}$ It has been demonstrated that the phosphatidylinositol-4 5-bisphosphate 3-kinase (PI3K)/AKT/mTOR pathway plays an important role in renal carcinogenesis and disease progression, ${ }^{25,26}$ and mTOR is the key downstream molecule of the PI3K/AKT pathway. Activation of mTOR promotes proliferation and survival of tumor cells and metabolism. It is also involved in proangiogenic signaling pathways in endothelial cells. Thus, mTOR can be taken as a central target for targeted RCC therapy. Everolimus, a specific mTOR inhibitor that can be orally administered, was approved for patients with advanced RCC refractory or intolerant to TKI therapy by the Chinese FDA in January 2013. This might facilitate the improvement of targeted therapy for advanced RCC. However, clinical evaluation of the efficacy and toxicity of everolimus in Chinese RCC patients is quite limited and preliminary. Most of the clinical studies are just registered and ongoing.

\section{Efficacy}

Guo et $\mathrm{a}^{27}$ conducted an open-label, multicenter, Phase Ib clinical trial in metastatic RCC (clinical trials.gov identifier NCT01152801). As shown in Table 1, of 64 patients with metastatic RCC either intolerant to previous VEGF receptorTKI therapy or progressed after therapy, three patients had a partial response, 39 patients had stable disease after treatment with everolimus, and no patient had a complete response. In that study, the median PFS was 6.9 months, which was much longer than the data obtained from the multicenter, randomized, double-blind, placebo-controlled, Phase III trial known as RECORD-1 (Renal Cell cancer treatment with Oral RAD001 given Daily)..$^{28,29}$ In addition, Huang et a ${ }^{30}$ retrospectively observed the therapeutic effect of everolimus in 24 patients with metastatic RCC who had previously received sorafenib or sunitinib or both treatments in Taiwan. None of these patients had a complete or partial response. However, $62.5 \%$ had stable disease and the median PFS was 7.1 months. The PFS was similar to that in Guo's study. ${ }^{27}$ Kato et al ${ }^{31}$ reviewed 19 Japanese patients with metastatic RCC and found a similar PFS. However, Park et $\mathrm{al}^{32}$ reviewed 100 Korean patients with metastatic RCC who received everolimus as second-line treatment and found that the median PFS was 4.2 months, which is consistent with the PFS in RECORD$1^{28}$ and RECORD-1 (updated). ${ }^{29}$ The inconsistency in the therapeutic effect of everolimus in the four Asian studies might be explained by two factors. First, the sample size was small, and the population sample size needs to be larger to verify if everolimus as second-line targeted therapy is suitable for Asian patients with metastatic RCC. Second, the RCC histology was not consistent. Histology type is an important predictor of therapeutic response to everolimus, because everolimus favors the clear cell type over other types. All tumor histology was of the clear cell type in the study by Guo et al and in the RECORD-1 trial, whereas non-clear cell types were also enrolled in other studies (Table 1). In addition, clinical risk categories might affect the clinical response. The patients in the study by Guo et al and those in RECORD- 1 had a Karnofsky performance status of at least $70 \%$; however, the risk categories were not presented in the study by Guo et al. Nevertheless, Asian patients might respond better than or similar to Western patients.

Another open-label, multicenter, randomized, Phase I clinical study carried out in Chinese patients with advanced breast cancer, gastric cancer, non-small cell lung cancer, or RCC has demonstrated that everolimus at a dose of $5 \mathrm{mg}$ or $10 \mathrm{mg}$ per day is well tolerated in Chinese patients, and the most common adverse effects are mild to moderate in 


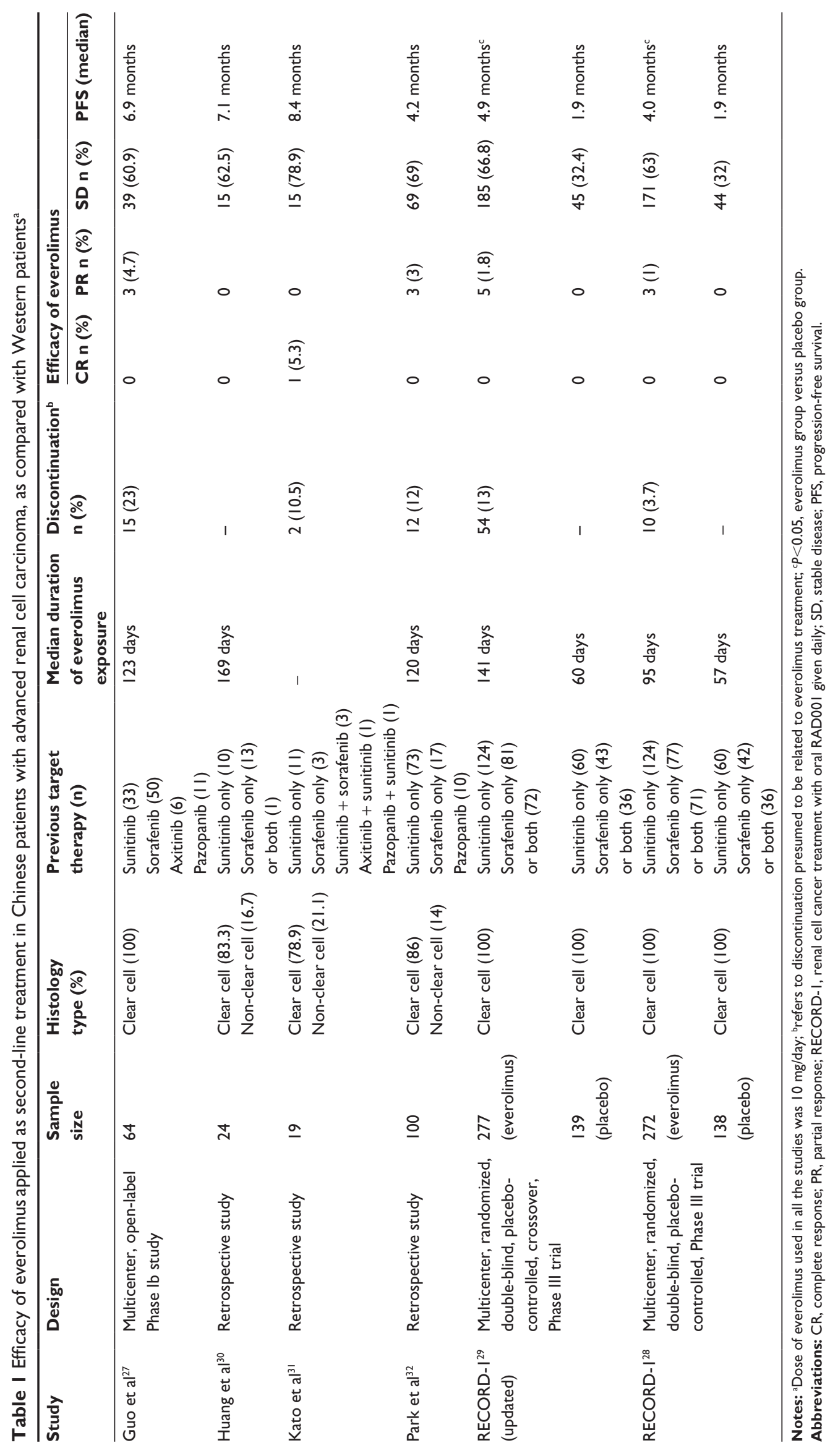


intensity. ${ }^{33}$ These two dose levels of everolimus share a similar adverse effect profile, except that more patients in the $10 \mathrm{mg}$ /day group suffered adverse effects than those in the $5 \mathrm{mg} /$ day group. These adverse effects include hyperglycemia, fatigue, and anemia, and are manageable with careful monitoring. This study indicates that everolimus may benefit patients with RCC more than those with other types of cancer, because RCC patients can stand for the longest median duration of everolimus treatment of 184.5 days among the patients with cancer of these histotypes.

\section{Safety}

Rates of discontinuation due to side effects range from 3.7\% to $23.0 \%$ in the studies of everolimus (Table 1). In addition, approximately one third of patients need drug interruption or dose reduction due to adverse effects. However, judicious dose reductions may prolong the duration of everolimus treatment, thus contributing to prolonged overall survival in Asian and non-Asian patients. ${ }^{34}$ Guo et $\mathrm{al}^{27}$ documented that $42 \%$ of RCC patients reported more than one adverse effect related to treatment with everolimus. As shown in Table 2, the most common adverse effects were anemia, mouth ulceration, pyrexia, fatigue, rash, hypertriglyceridemia, hypercholesterolemia, hyperglycemia, and noninfectious pneumonitis, ie, a toxicity profile similar to that seen in Western patients. Among these adverse effects, mouth ulceration, pyrexia, rash, and noninfectious pneumonitis occurred more often in Chinese patients than in Western patients, whereas metabolic abnormalities, including anemia, hypertriglyceridemia, and hypercholesterolemia, occurred more often in Western patients than in Chinese patients..$^{28,29}$ Such a trend was also seen in another group of Chinese patients in Taiwan, ${ }^{30}$ indicating that differences in genetic background may contribute to the difference in everolimus-related metabolism seen between Chinese and Western patients. Pneumonitis is a toxicity associated with rapamycin and rapamycin analogs, and Chinese patients have high rates of pneumonitis of all grades or pneumonitis of grades $3 / 4$ (Table 2 ). Kato et $\mathrm{al}^{31}$ also found that Japanese patients suffered more severe pneumonitis. Specifically, anemia occurred more in Chinese patients of grades $3 / 4$ than in Western patients of the same grades though it was less in Chinese patients with adverse effects of all grades, which reminds Chinese health care providers to pay more attention to the special adverse effects due to cumulative toxicity of TKIs $^{35}$ and minimize the risk of deterioration.

Although everolimus rarely results in a complete response, it can stabilize the disease as well as prolong PFS and overall survival. Everolimus has advantages when compared with temsirolimus and sorafenib ${ }^{36}$ as second-line targeted treatments in RCC patients, regardless of the initial targeted therapy used. Because of its comparable safety and ability to be administered orally, everolimus could improve quality of life for Chinese RCC patients who are resistant to first-line TKIs.

\section{Sequential targeted therapy}

Although several targeted agents are proven to be effective in improving the treatment of patients with advanced RCC, most patients eventually develop drug resistance and disease progression. Thus, sequential targeted therapy may yield more clinical benefit via a tailored therapy design. Motzer et $\mathrm{al}^{37}$ performed a large, randomized, multicenter Phase II trial (RECORD-3) that compared sequential first-line everolimus and second-line sunitinib versus first-line sunitinib and second-line everolimus in patients with metastatic RCC using a crossover treatment design. Compared with sunitinib alone, treatment with everolimus resulted in a shorter median PFS (7.9 months versus 10.7 months, hazard ratio 1.4, 95\% confidence interval 1.2-1.8). Compared with the everolimussunitinib paradigm, the sunitinib-everolimus paradigm might contribute to longer median PFS (25.8 months versus 21.1 months, hazard ratio $1.3,95 \%$ confidence interval $0.9-1.7$ ) and overall survival (32.0 months versus 22.4 months, hazard ratio $1.2,95 \%$ confidence interval $0.9-1.6$ ), although this contribution did not reach a statistically significant level. The sunitinib-everolimus paradigm is still recommended as standard therapy. Li et a $\mathrm{l}^{38}$ undertook sequential targeted therapy in Chinese patients with metastatic RCC in Taiwan and reported that second-line everolimus achieved a fair degree of disease control in patients whose first-line sunitinib treatment resulted in primary resistance. However, the therapeutic efficacy of sequential targeted therapy using everolimus is rarely confirmed in Chinese patients. Thus, the role of everolimus in sequential targeted therapy for Chinese patients needs to be explored in more depth and verified by clinical studies with a large sample size and rigorous design.

\section{Prediction of efficacy of everolimus}

The therapeutic efficacy of everolimus depends on the unique and indispensible role of the PI3K/AKT/mTOR pathway in the progression of metastatic RCC. The efficacy can be greatly reduced by feedback loops, given that the PI3K/AKT/mTOR pathway has crosstalk with other important signaling pathways, including the CXCR4-CXCL12-CXCR7 chemokine receptor axis, the nuclear factor $\mathrm{\kappa B}$ pathway, and the hedgehog pathway. ${ }^{39-41}$ Thus, clarification of the role of the PI3K/ 


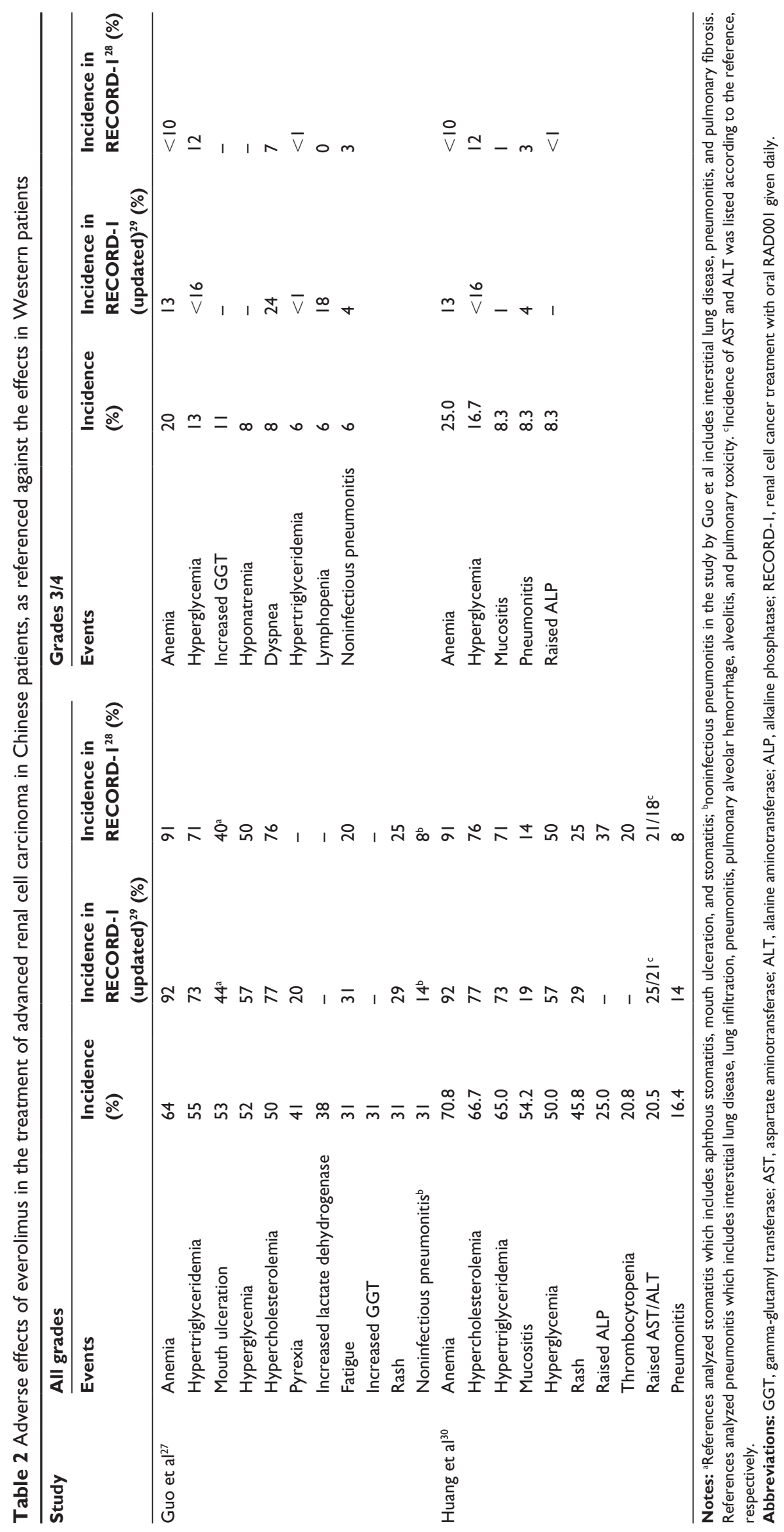


Table 3 Agents approved for targeted treatment of advanced renal cell carcinoma in Mainland China

\begin{tabular}{|c|c|c|c|c|}
\hline $\begin{array}{l}\text { Targeting } \\
\text { agents }\end{array}$ & $\begin{array}{l}\text { Date admitted } \\
\text { in Mainland China }\end{array}$ & $\begin{array}{l}\text { Recommendation } \\
\text { therapy }\end{array}$ & Efficacy in Chinese patients & Common adverse effects \\
\hline Sorafenib & November 2006 & First-line & $\begin{array}{l}\text { More effective in Chinese than Western patients } \\
\text { Well tolerated } \\
\text { Dose escalation in certain patients }\end{array}$ & $\begin{array}{l}\text { Hand-foot syndrome, diarrhea, } \\
\text { fatigue, loss of appetite, alopecia }\end{array}$ \\
\hline Sunitinib & May 2008 & First-line & $\begin{array}{l}\text { Similar effective with sorafenib } \\
\text { Higher toxicity in Chinese than Western patients } \\
\text { Dose reduction required in certain patients }\end{array}$ & $\begin{array}{l}\text { Thrombocytopenia, hypothyroidism, } \\
\text { neutropenia, hand-foot syndrome, } \\
\text { hypertension }\end{array}$ \\
\hline Everolimus & January 2013 & After TKI failure & $\begin{array}{l}\text { More effective in Chinese than Western patients } \\
\text { Rarely yields complete response } \\
\text { Well tolerated } \\
\text { Dose reduction required in certain patients }\end{array}$ & $\begin{array}{l}\text { Mouth ulceration, pyrexia, rash, } \\
\text { noninfectious pneumonitis, anemia }\end{array}$ \\
\hline
\end{tabular}

Abbreviation: TKI, tyrosine kinase inhibitor.

AKT/mTOR-centered signaling network and the mutation pattern of hub genes ${ }^{42}$ in this network in renal carcinogenesis and progression, will be helpful in designing everolimusbased sequential targeted therapy. Recently, Santoni et al ${ }^{43}$ systematically summarized the major pathways that have crosstalk with the PI3K/AKT/mTOR pathway and the sites of mutation in the PI3K/AKT/mTOR network, including PI3K, PTEN, and phosphorylated 4E-binding protein 1 that could result in resistance to everolimus therapy. The effect of these pathways and somatic mutations on resistance to everolimus therapy should be systematically evaluated in the Chinese population. Understanding the mechanisms by which metastatic RCC cells develop resistance to mTOR inhibitors may lead to identification of more efficient and specific ways to overcome resistance to everolimus and facilitate prognostication in patients with advanced RCC.

Using immunohistochemistry, a study by Li et al ${ }^{44}$ (clinical trials.gov identifier NCT01152801) found that positive expression of phosphorylated mTOR in paraffinembedded tumor tissue specimens from Chinese patients with TKI-refractory metastatic RCC was significantly associated with a better clinical benefit rate and longer PFS on everolimus and that positive expression of phosphorylated $40 \mathrm{~S}$ ribosomal protein $\mathrm{S} 6$ was significantly associated with a longer PFS on everolimus. The expression level of phosphorylated 4E-binding protein 1 was shown to be an independent predictor of the response to treatment with $\mathrm{mTOR}$ inhibitors in Japanese patients with metastatic RCC..$^{45}$ The pretreatment neutrophil-to-lymphocyte ratio in peripheral blood has been shown to be an independent prognostic factor for patients with metastatic RCC who received everolimus as second-line or third-line treatment. ${ }^{46}$ When the neutrophil-to-lymphocyte ratio was less than 3, the median PFS and OS in this study was 9.9 months and 24.4 months, ie, longer than the corresponding results in the RECORD-1 trial. As the activation profile of the signal network has better specificity and sensitivity than individual genes in predicting the prognosis of cancer patients, ${ }^{47}$ the presence of the above-mentioned molecules or cells in clinical samples from increasing clinical trials of everolimus can be used to develop a prognostic system to improve the outlook for patients with metastatic RCC, thus guiding clinical decision-making.

\section{Conclusion}

In summary, we have outlined the recent progress in use of targeted therapies for advanced RCC in the People's Republic of China (Table 3), in particular treatment using everolimus. Compared with Western patients, Chinese patients with advanced or metastatic RCC respond better to sorafenib and sunitinib as first-line targeted therapy, but sunitinib has a relatively higher rate of toxicity. Everolimus, an mTOR inhibitor that can be orally administered, is well tolerated and acceptable for Chinese patients. Everolimus has competitive advantages as second-line targeted treatment for Chinese patients with advanced or metastatic RCC who are resistant to first-line TKIs. Although most studies of targeted therapies for advanced RCC have obvious limitations, such as small sample size and retrospective design, the evidence so far indicates that everolimus should be effective as secondline targeted therapy for advanced RCC in the People's Republic of China.

\section{Acknowledgment}

This study was supported by the National Natural Science Foundation of China (81101928).

\section{Disclosure}

The authors report no conflicts of interest in this work.

\section{References}

1. Jemal A, Bray F, Center MM, Ferlay J, Ward E, Forman D. Global cancer statistics. CA Cancer J Clin. 2011;61(2):69-90. 
2. International Agency for Research on Cancer. Globocan 2012. Available from: http://globocan.iarc.fr/Default.aspx. Accessed January 15, 2015.

3. Escudier B, Eisen T, Stadler WM, et al. Sorafenib in advanced clear-cell renal-cell carcinoma. $N$ Engl J Med. 2007;356(2): 125-134.

4. Ricketts CJ, Linehan WM. Intratumoral heterogeneity in kidney cancer. Nat Genet. 2014;46(3):214-215.

5. Hofmann JN, Corley DA, Zhao WK, et al. Chronic kidney disease and risk of renal cell carcinoma: differences by race. Epidemiology. 2015; 26(1):59-67.

6. Sun Y, Na Y, Yu S, et al. Sorafenib in the treatment of Chinese patients with advanced renal cell cancer. J Clin Oncol. 2008;26 Suppl:Abstr 16127.

7. Guo F, Xie XD, Liu ZZ, et al. Prognostic analysis of Chinese patients with metastatic renal cell cancer $(\mathrm{mRCC})$ receiving sorafenib: a multicenter retrospective study. J Clin Oncol. 2013;31 Suppl:Abstr e15582.

8. Yang L, Shi L, Fu Q, et al. Efficacy and safety of sorafenib in advanced renal cell carcinoma patients: results from a long-term study. Oncol Lett. 2012;3(4):935-939.

9. Zhang H, Dong B, Lu JJ, et al. Efficacy of sorafenib on metastatic renal cell carcinoma in Asian patients: results from a multicenter study. $B M C$ Cancer. 2009;9:249

10. Walter M, Stadler MD, Robert A, et al. Safety and efficacy results of the advanced renal cell carcinoma sorafenib expanded access program in North America. Cancer. 2010;116(5):1272-1280.

11. Beck J, Procopio G, Bajetta E, et al. Final results of the European Advanced Renal Cell Carcinoma Sorafenib (EU-ARCCS) expandedaccess study: a large open-label study in diverse community settings. Ann Oncol. 2011;22(8):1812-1823.

12. Tanigawa G, Kawashima A, Yamaguchi S, et al. Clinical outcome and prognostic factors of sorafenib in Japanese patients with advanced renal cell carcinoma in general clinical practice. Jpn J Clin Oncol. 2011; 41(11):1265-1270.

13. Park SJ, Lee JL, Park I, et al. Comparative efficacy of sunitinib versus sorafenib as first-line treatment for patients with metastatic renal cell carcinoma. Chemotherapy. 2012;58(6):468-474.

14. Zhang HL, Ye DW, Yao XD, et al. [Clinical evaluation of sorafenib dose escalation after failure to conventional dosage in advanced renal cell carcinoma]. Zhonghua Bi Niao Wai Ke Za Zhi. 2010;31:24-27. Chinese.

15. Ye DW, Zhang HL. Critical appraisal of sorafenib in the treatment of Chinese patients with renal cell carcinoma. Onco Targets Ther. 2014; 7:925-935.

16. Mihaly Z, Sztupinszki Z, Surowiak P, Gyorffy B. A comprehensive overview of targeted therapy in metastatic renal cell carcinoma. Curr Cancer Drug Targets. 2012;12(7):857-872.

17. Ye DW, Shi GH. [Application of sunitinib for the treatment of advanced renal cell carcinoma in China: phase IV clinical trial]. Zhonghua Bi Niao Wai Ke Za Zhi. 2012;33(4):245-246. Chinese.

18. Motzer RJ, Hutson TE, Tomczak P, et al. Sunitinib versus interferon alfa in metastatic renal-cell carcinoma. $N$ Engl J Med. 2007;356(2): 115-124.

19. Motzer RJ, Hutson TE, Tomczak P, et al. Overall survival and updated results for sunitinib compared with interferon alfa in patients with metastatic renal cell carcinoma. J Clin Oncol. 2009;27(22): 3584-3590.

20. He Z, Guo G, Zhang C, et al. Efficacy of sunitinib in patients with metastatic renal cell carcinoma: initial experience in two Chinese centers. Chin Med J (Engl). 2014;127(8):1450-1453.

21. Yoo C, Kim JE, Lee JL, et al. The efficacy and safety of sunitinib in Korean patients with advanced renal cell carcinoma: high incidence of toxicity leads to frequent dose reduction. Jpn J Clin Oncol. 2010;40(10): 980-985.
22. Kim HR, Park HS, Kwon WS, et al. Pharmacogenetic determinants associated with sunitinib-induced toxicity and ethnic difference in Korean metastatic renal cell carcinoma patients. Cancer Chemother Pharmacol. 2013;72(4):825-835.

23. Kim HS, Hong MH, Kim K, et al. Sunitinib for Asian patients with advanced renal cell carcinoma: a comparable efficacy with different toxicity profiles. Oncology. 2011;80(5-6):395-405.

24. Négrier S, Gravis G, Pérol D, et al. Temsirolimus and bevacizumab, or sunitinib, or interferon alfa and bevacizumab for patients with advanced renal cell carcinoma (TORAVA): a randomised phase 2 trial. Lancet Oncol. 2011;12(7):673-680.

25. Linehan WM, Srinivasan R, Schmidt LS. The genetic basis of kidney cancer: a metabolic disease. Nat Rev Urol. 2010;7(5):277-285.

26. Hager M, Haufe H, Lusuardi L, Schmeller N, Kolbitsch C. p-AKT overexpression in primary renal cell carcinomas and their metastases. Clin Exp Metastasis. 2010;27(8):611-617.

27. Guo J, Huang Y, Zhang X, et al. Safety and efficacy of everolimus in Chinese patients with metastatic renal cell carcinoma resistant to vascular endothelial growth factor receptor-tyrosine kinase inhibitor therapy: an open-label phase 1b study. BMC Cancer. 2013;13:136.

28. Motzer RJ, Escudier B, Oudard S, et al. Efficacy of everolimus in advanced renal cell carcinoma: a double-blind, randomised, placebocontrolled phase III trial. Lancet. 2008;372(9637):449-456.

29. Motzer RJ, Escudier B, Oudard S, et al. Phase 3 trial of everolimus for metastatic renal cell carcinoma: final results and analysis of prognostic factors. Cancer. 2010;116(18):4256-4265.

30. Huang WK, Liaw CC, Pang ST, et al. Everolimus in metastatic renal cell carcinoma: preliminary experience from Chang Gung Memorial Hospital. Chang Gung Med J. 2012;35(5):402-407.

31. Kato R, Obara W, Matsuura T, Kato Y, Iwasaki K, Fujioka T. Efficacy of everolimus in patients with advanced renal cell carcinoma refractory or intolerant to VEGFR-TKIs and safety compared with prior VEGFRTKI treatment. Jpn J Clin Oncol. 2014;44(5):479-485.

32. Park K, Lee JL, Ahn JH, et al. Efficacy and safety of everolimus in Korean patients with metastatic renal cell carcinoma following treatment failure with a vascular endothelial growth factor receptor-tyrosine kinase inhibitor. Cancer Res Treat. 2014;46(4):339-347.

33. Xu B, Wu Y, Shen L, et al. Two-dose-level confirmatory study of the pharmacokinetics and tolerability of everolimus in Chinese patients with advanced solid tumors. J Hematol Oncol. 2011;4:3.

34. Wang Y, Choueiri TK, Lee JL, et al. Anti-VEGF therapy in mRCC: differences between Asian and non-Asian patients. Br J Cancer. 2014; 110(6):1433-1437.

35. Calvo E, Grünwald V, Bellmunt J. Controversies in renal cell carcinoma: treatment choice after progression on vascular endothelial growth factor-targeted therapy. Eur J Cancer. 2014;50(7):1321-1329.

36. Wong MK, Yang H, Signorovitch JE, et al. Comparative outcomes of everolimus, temsirolimus and sorafenib as second targeted therapies for metastaticrenal cell carcinoma: a US medical record review. Curr Med Res Opin. 2014;30(4):537-545.

37. Motzer RJ, Barrios CH, Kim TM, et al. Phase II randomized trial comparing sequential first-line everolimus and second-line sunitinib versus firstline sunitinib and second-line everolimus in patients with metastatic renal cell carcinoma. J Clin Oncol. 2014;32(25):2765-2772.

38. Li JR, Yang CK, Wang SS, et al. First-line treatment result influence second-line regimen selection in targeted therapy for metastatic renal cell carcinoma. Anticancer Res. 2014;34(10):5643-5647.

39. Ieranò $C$, Santagata $S$, Napolitano M, et al. CXCR4 and CXCR7 transduce through mTOR in human renal cancer cells. Cell Death Dis. 2014;5:e1310.

40. Agouni A, Sourbier C, Danilin S, et al. Parathyroid hormone-related protein induces cell survival in human renal cell carcinoma through the PI3K Akt pathway: evidence for a critical role for integrin-linked kinase and nuclear factor kappa B. Carcinogenesis. 2007;28(9):1893-1901. 
41. Brechbiel J, Miller-Moslin K, Adjei AA. Crosstalk between hedgehog and other signaling pathways as a basis for combination therapies in cancer. Cancer Treat Rev. 2014;40(6):750-759.

42. Cancer Genome Atlas Research Network. Comprehensive molecular characterization of clear cell renal cell carcinoma. Nature. 2013;499(7456): 43-49.

43. Santoni M, Pantano F, Amantini C, et al. Emerging strategies to overcome the resistance to current mTOR inhibitors in renal cell carcinoma. Biochim Biophys Acta. 2014;1845(2):221-231.

44. Li S, Kong Y, Si L, et al. Phosphorylation of mTOR and S6RP predicts the efficacy of everolimus in patients with metastatic renal cell carcinoma. BMC Cancer. 2014;14:376.
45. Nishikawa M, Miyake H, Harada K, Fujisawa M. Expression level of phosphorylated-4E-binding protein 1 in radical nephrectomy specimens as a prognostic predictor in patients with metastatic renal cell carcinoma treated with mammalian target of rapamycin inhibitors. Med Oncol. 2014;31(1):792.

46. Santoni M, De Giorgi U, Iacovelli R, et al. Pre-treatment neutrophil-to-lymphocyte ratio may be associated with the outcome in patients treated with everolimus for metastatic renal cell carcinoma. $\mathrm{Br}$ J Cancer. 2013;109(7):1755-1759.

47. Borisov NM, Terekhanova NV, Aliper AM, et al. Signaling pathway activation profiles make better markers of cancer than expression of individual genes. Oncotarget. August 23, 2014. [Epub ahead of print].

\section{Publish your work in this journal}

OncoTargets and Therapy is an international, peer-reviewed, open access journal focusing on the pathological basis of all cancers, potential targets for therapy and treatment protocols employed to improve the management of cancer patients. The journal also focuses on the impact of management programs and new therapeutic agents and protocols on

\section{Dovepress}

patient perspectives such as quality of life, adherence and satisfaction. The manuscript management system is completely online and includes a very quick and fair peer-review system, which is all easy to use. Visit http://www.dovepress.com/testimonials.php to read real quotes from published authors.

Submit your manuscript here: http://www.dovepress.com/oncotargets-and-therapy-journal 